\title{
US Budget Impact Model for Selinexor, Bortezomib, and Dexamethasone for the Treatment of Previously Treated Multiple Myeloma
}

\author{
Mike Dolph' \\ Gabriel Tremblay' \\ Hoyee Leong ${ }^{2}$
}

'Health Economics Department, Purple Squirrel Economics, New York, NY, 10010, USA; ${ }^{2}$ Health Economics and Outcomes Research, Global Medical and Scientific Affairs, Karyopharm

Therapeutics, Newton, MA, 02459, USA
Purpose: To estimate the budget impact of selinexor, bortezomib, and dexamethasone $(\mathrm{XVd})$ in patients with previously treated multiple myeloma $(\mathrm{MM})$ from the perspective of a private third-party payer and Medicare in the US.

Methods: The introduction of XVd as an option for patients with previously treated MM compared to no introduction of XVd was considered from a private third-party US payer (with 1,000,000 members) and a Medicare perspective in one-year increments for 3 years. Total annual treatment costs were calculated as the sum of drug costs, costs of treating serious treatment emergent adverse events (grade $\geq 3$ ), ongoing best supportive care costs, and mortality costs.

Results: The absolute budget impact (Millions, USD) of including XVd from a private thirdparty payer plan perspective was $\$ 0.06, \$ 0.07, \$ 0.08$ and $\$ 0.22$ for years $1,2,3$, and overall, respectively. The relative budget impact of including XVd was $0.33 \%, 0.40 \%, 0.43 \%$, and $0.38 \%$ for years $1,2,3$, and overall, respectively. This translated to a per member per month (PMPM) budget impact of $\$ 0.005, \$ 0.006, \$ 0.007$, and $\$ 0.006$ (USD), for years $1,2,3$, and overall, respectively. From a Medicare perspective, the absolute budget impact (Millions, USD) of including XVd was $\$ 29.68, \$ 36.62, \$ 39.42$ and $\$ 105.72$ for years $1,2,3$, and overall, respectively. The relative budget impact of including XVd was $0.33 \%, 0.40 \%$, $0.43 \%$, and $0.38 \%$ percent for years $1,2,3$, and overall, respectively. This translated to a PMPM budget impact of $\$ 0.041, \$ 0.051, \$ 0.054$, and $\$ 0.049$ (USD), for years $1,2,3$, and overall, respectively. Sensitivity analyses showed general consistency with the base-case findings.

Conclusion: Understanding the potential budget impact of new therapies in MM is vital for payers to manage spending and assess treatment value. The introduction of XVd presents a manageable budget impact for a third-party US payer and Medicare.

Keywords: budget impact, multiple myeloma, Xpovio, selinexor, XVd, relapsed or refractory multiple myeloma

\section{Introduction}

As the second most common hematological malignancy after non-Hodgkin's lymphoma in the United States (US), multiple myeloma (MM) was estimated to represent nearly $2 \%$ of all new cancer cases and over $2 \%$ of all cancer deaths in 2020 with approximately 32,270 new cases and 12,830 deaths. ${ }^{1}$ The treatment of MM has improved in the last two decades, first from the use of high-dose chemotherapy with alkylating agents and autologous stem cell transplantation (SCT), and
Correspondence: Hoyee Leong Email hleong@karyopharm.com 
subsequently to the introduction of immunomodulatory agents (IMiDs; thalidomide, lenalidomide, and pomalidomide), proteasome inhibitors (PIs; bortezomib, carfilzomib and ixazomib), and monoclonal antibodies (daratumumab, elotuzumab, and isatuximab). Despite the approval of a variety of therapies in recent years, MM largely remains an incurable and fatal disease as nearly all patients relapse following each of their sequential therapies, ultimately developing progressive, refractory disease.

In the US, bortezomib has been approved for the treatment of MM in combination with a variety of agents and has a broad label and multiple recommendations for use in the National Comprehensive Cancer Network guidelines. ${ }^{2,3}$ However, the approved regimens for previously treated MM utilize twice-weekly dosing of bortezomib which must be administered in the clinic. This dosing frequency can be burdensome for patients, caregivers, and the healthcare system. ${ }^{4}$ Moreover, this twice-weekly dosing frequency of bortezomib induces significant sensory and motor peripheral neuropathy (PN). Peripheral neuropathy, with reported rates of $35 \%$ to $55 \%$ in doublet and triplet regimens, often leads to treatment interruptions, dose reductions, treatment discontinuation, and ultimately, loss of therapeutic efficacy. ${ }^{5-7}$ PN can be minimized with once-weekly bortezomib therapy, and many physicians employ once weekly bortezomib-based regimens. ${ }^{8}$ Thus, developing novel therapies that demonstrate clinical benefits with once weekly bortezomib will serve a current and rapidly growing unmet medical need in patients with previously treated MM. A once weekly bortezomib-based regimen may provide reduced clinic visits, improved progression-free survival (PFS) and overall response rate (ORR) over twice-weekly bortezomib and moderate dose dexamethasone $(\mathrm{Vd})$, and reduced PN-associated side effects of bortezomib. ${ }^{6,7,9,10}$

As an oral, first-in-class selective inhibitor of nuclear export (SINE) compound, selinexor (XPOVIO; Karyopharm Therapeutics, Inc.) works in combination with both bortezomib (and other PIs) and dexamethasone to selectively kill malignant plasma cells. ${ }^{11}$ The US Food and Drug Administration (FDA) has approved selinexor in combination with bortezomib and dexamethasone for the treatment of adult patients with previously treated $\mathrm{MM} .{ }^{11}$ In the ongoing BOSTON (Bortezomib, Selinexor, and low dose dexamethasone [XVd] Treatment in Patients with Multiple Myeloma) Phase 3 trial (NCT03110562), adult patients with MM previously treated with one to three lines of therapy, including PIs, were randomly allocated (1:1) to receive XVd $(n=195)$ or $\operatorname{Vd}(n=207)$. This once weekly triplet XVd therapy was superior to standard twice weekly $\mathrm{Vd}$ despite using $40 \%$ less bortezomib and $25 \%$ less dexamethasone during the first 24 weeks of treatment than the control arm. In addition to this, $\mathrm{XVd}$ demonstrated superior results in nearly all efficacy endpoints (PFS, ORR, greater than or equal to very good partial response $[\geq \mathrm{VGPR}]$, and duration of response [DOR]) compared to $\mathrm{Vd}$ across all patient subgroups, including elderly, frail, bortezomib-naïve, and lenalidomide-pretreated patients and in patients with high-risk cytogenetics. ${ }^{12}$ With the once weekly dosing of bortezomib, there were $\sim 37 \%$ fewer clinic visits on XVd compared with the standard Vd control arm. ${ }^{12}$ In addition, the XVd treatment arm was associated with significantly reduced rates of $\mathrm{PN}$, the most common long-term toxicity associated with bortezomib. Bortezomib-induced PN is associated with substantially reduced health-related quality of life (HRQoL) in patients with MM. ${ }^{13}$

Although new therapies can be associated with increases in the cost of care for previously treated MM, improvements in life expectancy have been realized: five-year survival has improved from $27 \%$ in 1989 to $55.6 \%$ in 2017 for all stages of MM combined. ${ }^{1,14}$ Quantifying and understanding potential budget impacts of new therapies in MM is vital for payers to manage costs and assess the value of new therapies. ${ }^{15}$ From 2000 to 2014, per member per month (PMPM) treatmentrelated drug costs for patients with $\mathrm{MM}$ rose from $\$ 346$ to $\$ 4,179$, accounting for an estimated $28.5 \%$ of total healthcare costs for these patients. ${ }^{16}$ Understanding the potential budget impacts of different therapy options supports the development of value-based frameworks; for example the American Society of Clinical Oncology (ASCO) utilizes these costs in its calculation of net health benefits. ${ }^{17-19}$

Building off of a previous budget impact model evaluating selinexor as monotherapy in penta-refractory MM, this work developed an Excel-based budget impact model for XVd from (1) a private US payer perspective and (2) a Medicare perspective, comparing two scenarios for previously treated MM patients: one without the introduction of XVd (Status quo) versus one with the introduction of XVd (XVd scenario). ${ }^{19}$

\section{Materials and Methods}

Model Characteristics: Perspective, Time

\section{Horizon, Structure}

Similar to a previous study of the budget impact of selinexor, the budget impact of XVd was compared to the 
status-quo assessed from the perspective of a US private third-party payer and a Medicare perspective. ${ }^{19}$ The budget impact analysis followed guidelines for economic evaluations in support of formulary listings set by the International Society for Pharmacoeconomics and Outcomes Research (ISPOR) and the Academy of Managed Care Pharmacy (AMCP). ${ }^{19-22}$ A schematic of the budget impact model is shown in Figure 1.

To determine total annual treatment costs and assess the projected budget impact of XVd as a treatment option, the model considered costs of primary therapy, secondary therapy (ie, therapy received once patients discontinue their primary therapy, based on the market shareweighted average benefits and costs of all included regimens), administration, routine medical care, serious treatment emergent adverse events (TEAEs), and mortality. All costs were presented in 2020 US dollars and undiscounted, as is standard practice and in alignment with AMCP and ISPOR guidelines. ${ }^{20-22}$ Similar to previous budget impact models, a key assumption was that the use of $\mathrm{XVd}$ would not significantly reduce the costs of supportive care that patients would continue to require to address complications of MM such as anemia or infections. ${ }^{19,23}$ The analysis was conducted in one-year increments for the first 3 years after the introduction of $\mathrm{XVd}$. The inclusion of XVd was compared to a status quo (ie, without the introduction of $\mathrm{XVd}$ ).

\section{Model Population}

The number of XVd eligible patients was derived from the estimated proportion of adult patients (based on US estimates from 2018) with MM incidence per $100,000 .{ }^{14,24}$ Two populations were assessed: (1) using a hypothetical private third-party payer plan with a population of 1,000,000 (Supplementary Table 1), and (2) 59,499,015 members participating in Medicare (Supplementary Table 2). ${ }^{25}$ In addition to the Medicare population including a larger population base, they included an older population and therefore had a higher incidence of MM compared with the private third-party payer plan ( $0.035 \%$ versus $0.006 \%$ at the baseline year, respectively). ${ }^{14}$

\section{Treatment Parameters Medication Dosing, Duration, and Treatment Costs}

This model included XVd therapy as conducted in the BOSTON trial (NCT03110562). ${ }^{11}$ The model used

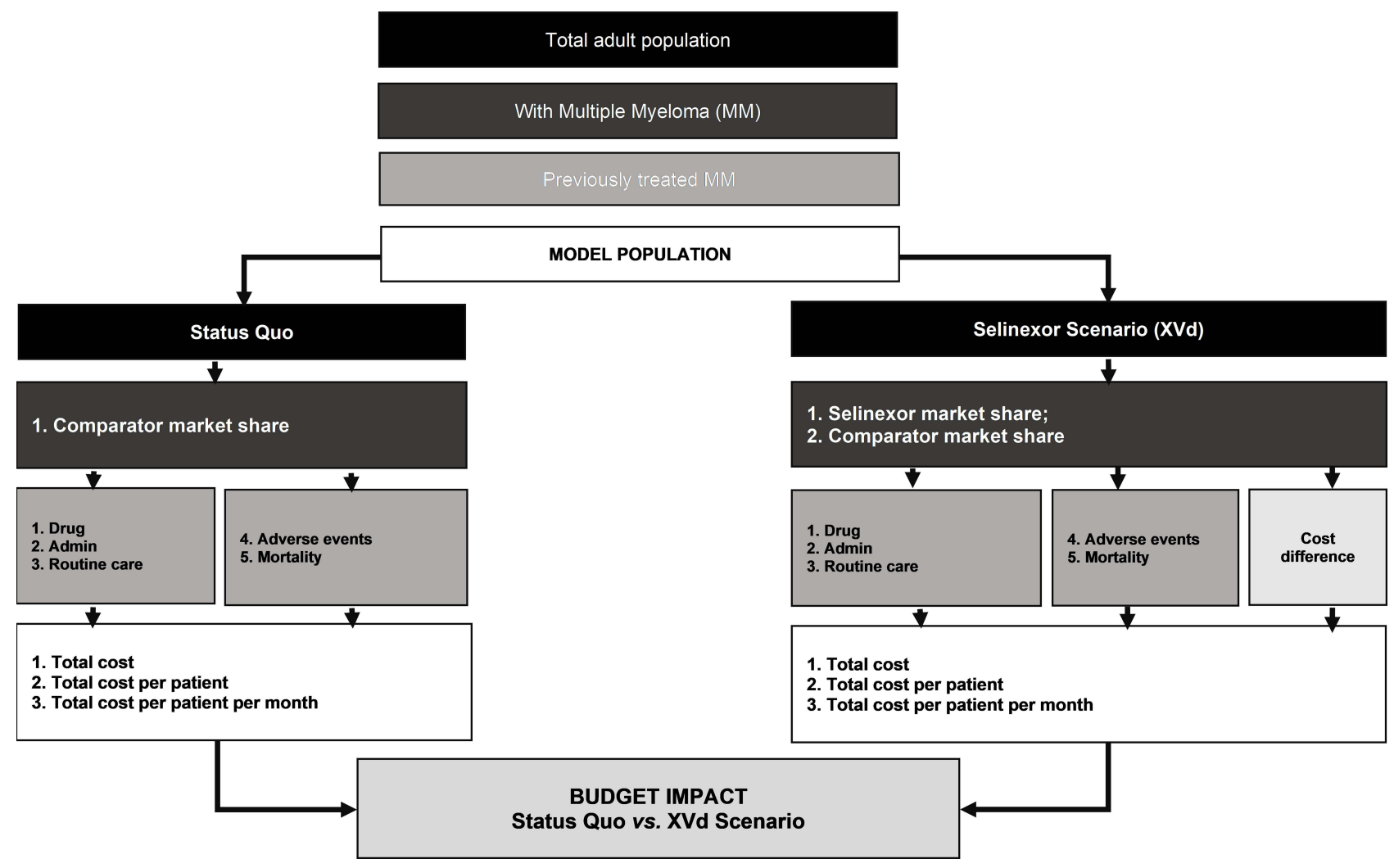

Figure I Budget Impact Model Conceptual Model. 
a dosage of selinexor (100 mg orally once per week), bortezomib $\left(1.3 \mathrm{mg} / \mathrm{m}^{2}\right.$ subcutaneously [SC] once per week), and dexamethasone (20 $\mathrm{mg}$ orally twice per week). The unit costs for selinexor, bortezomib and dexamethasone were set to wholesale acquisition costs (WAC) obtained from AnalySource. ${ }^{26}$ The WAC per package of selinexor containing 24 tablets of $20 \mathrm{mg}$ strength was $\$ 26,400$. No WAC discount was assumed in the basecase analysis.

Selinexor was given as a fixed oral $100 \mathrm{mg}$ dose (5 tablets of $20 \mathrm{mg}$ each) on Days 1, 8, 15, 22, and 29 of each 35-day cycle (ie, each week, QW), at a cost per month of $\$ 23,915$ (USD). Bortezomib was given subcutaneously at a dose of $1.3 \mathrm{mg} / \mathrm{m}^{2} \mathrm{SC}$ in the clinic on Days $1,8,15$, and 22 of each 35-day cycle (ie, 4 out of every 5 weeks), at a cost per month of $\$ 5,855$ (USD). Dexamethasone was given as an oral $20 \mathrm{mg}$ dose on Days 1, 2, 8, 9, 15, 16, 22, 23,29 , and 30 of each 35-day cycle, at a cost per month of $\$ 43$ (USD). The combined total cost per month of XVd treatment was $\$ 29,814$ (USD). The average per person drug cost for 1 year of treatment was calculated using the cost of drug dosage, frequency, and duration of treatment. While selinexor and dexamethasone are orally dosed, bortezomib is subcutaneously dosed, so wastage for bortezomib was considered in the model (ie, if there is remaining drug in a vial each administration, then the price of the entire vial is used; any unused drug in a vial will be discarded, this is applied on a per administration basis). In the base-case analysis, drug adherence for regimens was set to $100 \%$. Drug costs were not reduced by cost-sharing, co-insurance or co-payment. ${ }^{27}$ All other regimens were dosed according to US FDA dosing information or the relevant clinical trials if FDA labels were not available for a regimen. ${ }^{28-35}$

Overall and progression-free survival estimates for each regimen were based on their respective clinical trials. In the model, OS drove the mortality of patients while PFS dictated the treatment duration and the duration patients remained in the "progression-free" state where they incurred lower medical costs compared with the "postprogression" state.

\section{Market Share}

The model assumed a year 1 uptake for XVd of $5.9 \%$ and assumed to increase to $7.2 \%$ in year 2, while a peak market share of $7.7 \%$ was assumed at year $3 .^{36}$

\section{Adverse Events}

The model included grade 3 or higher treatmentemergent adverse events (TEAEs) that occurred in at least $5 \%$ of patients. ${ }^{36}$ Adverse event (AE) rates were based on the relevant clinical trials, while the unit costs for each TEAE were based on inpatient and outpatient costs using a weighted average based on the proportion of AEs that were severe in the BOSTON clinical trial (Supplementary Table 3) ${ }^{31-35,37}$ Adverse events requiring outpatient care were costed as an outpatient physician visit for an established patient (CPT code 99213), while adverse events requiring inpatient care were obtained from HCUPnet (2017) based on the relevant ICD-10 codes $^{38,39}$ All costs were inflated to 2020 values using the US Bureau of Labor Statistics CPI Disease Based Price index. ${ }^{23}$ Costs to treat each TEAE are shown in Supplementary Table 4, while unit costs for each resource used are shown in Supplementary Table 5.

\section{One-Way Sensitivity Analysis Methods}

One-way (deterministic) sensitivity analyses were performed, which independently varied key model parameters to assess which inputs have the greatest impact on the results when adjusted. Variations in epidemiology parameters, efficacy inputs, patient characteristics, as well as drug price and other costs were tested in the sensitivity analysis.

\section{Results}

\section{Population}

In the base-case analysis for a private third-party payer plan with 1,000,000 members, the baseline number of patients considered eligible for $\mathrm{XVd}$ ranged from 47 to 49 each year (of which 3 to 4 were projected to be treated with XVd). ${ }^{14,37,40,41}$ In the base-case analysis from the Medicare perspective $(59,499,015$ members at the baseline year), the annual number of patients considered eligible for XVd ranged from 22,892 to 23,425 (with 1,361 to 1,808 projected to be treated). ${ }^{14,25,36,40,41}$

\section{Costs}

In the base-case analysis, the total drug cost per month of XVd treatment was $\$ 29,813$ per patient. Treatment of severe TEAEs was estimated to cost $\$ 166$ per month for patients treated with $\mathrm{XVd}$. 
Total primary therapy costs for a private third-party payer plan with $1,000,000$ members with the introduction of XVd were $\$ 14.35, \$ 14.23$, and $\$ 14.09$ (Millions, USD) at years 1, 2 and 3, respectively. Without the introduction of XVd (ie, the status quo), total primary therapy costs were $\$ 14.17, \$ 14.02$, and $\$ 13.87$ (Millions, USD) at years 1,2 and 3, respectively.

Total medical costs, adverse event costs, and mortality costs were not notably different in either scenario, but secondary therapy costs were lower in the $\mathrm{XVd}$ scenario. Secondary therapy costs with the introduction of $\mathrm{XVd}$ were $\$ 1.83, \$ 1.78$, and $\$ 1.75$ (Millions, USD) at years 1 , 2 and 3, respectively, compared to $\$ 1.94, \$ 1.92$, and $\$ 1.90$ (Millions, USD) at years 1, 2 and 3, respectively, in the Status Quo scenario.
Details of total primary, secondary, and other costs for $\mathrm{XVd}$ and other therapies in both scenarios are presented in Table 1 and Figure 2.

\section{Net Budget Impact}

Budget impact results are presented in Table 2. From a private third-party payer plan perspective, the absolute budget impact (Millions, USD) of including XVd was $\$ 0.06, \$ 0.07, \$ 0.08$ and $\$ 0.22$ for years $1,2,3$, and in total, respectively (Supplementary Figure 1). The relative budget impact of including XVd was $0.33 \%, 0.40 \%$, $0.43 \%$, and $0.38 \%$ for years $1,2,3$, and in total, respectively (Supplementary Figure 2). This translated to a PMPM budget impact of $\$ 0.005, \$ 0.006, \$ 0.007$, and $\$ 0.006$ (USD), for years $1,2,3$, and in total, respectively.

Table I XVd Scenario Total Costs (Millions, USD)

\begin{tabular}{|c|c|c|c|c|c|c|c|c|}
\hline & \multicolumn{4}{|c|}{ Status Quo Scenario } & \multicolumn{4}{|c|}{ XVd Scenario } \\
\hline & Baseline & Year I & Year 2 & Year 3 & Baseline & Year I & Year 2 & Year 3 \\
\hline $\begin{array}{l}\text { Total Primary Therapy } \\
\text { Costs }\end{array}$ & 14.33 & 14.17 & 14.02 & 13.87 & 14.33 & 14.35 & 14.23 & 14.09 \\
\hline$X V d$ & 0.00 & 0.00 & 0.00 & 0.00 & 0.00 & 1.01 & 1.23 & 1.30 \\
\hline DPd & 3.53 & 3.50 & 3.46 & 3.42 & 3.53 & 3.29 & 3.21 & 3.16 \\
\hline DRd & 3.18 & 3.14 & 3.11 & 3.07 & 3.18 & 2.96 & 2.88 & 2.84 \\
\hline EPd & 1.94 & 1.92 & 1.90 & $\mathrm{I} .88$ & 1.94 & 1.81 & 1.76 & 1.73 \\
\hline KRd & 1.97 & 1.94 & 1.92 & 1.90 & 1.97 & $\mathrm{I} .83$ & 1.78 & 1.76 \\
\hline IRd & 0.93 & 0.92 & 0.91 & 0.90 & 0.93 & 0.87 & 0.84 & 0.83 \\
\hline Vd & 0.26 & 0.26 & 0.25 & 0.25 & 0.26 & 0.24 & 0.24 & 0.23 \\
\hline Rd & 1.73 & 1.71 & 1.69 & 1.67 & 1.73 & 1.61 & 1.57 & 1.54 \\
\hline DAR & 0.16 & 0.15 & 0.15 & 0.15 & 0.16 & 0.14 & 0.14 & 0.14 \\
\hline DRVd & 0.32 & 0.32 & 0.32 & 0.31 & 0.32 & 0.30 & 0.29 & 0.29 \\
\hline Pd & 0.32 & 0.31 & 0.31 & 0.31 & 0.32 & 0.29 & 0.29 & 0.28 \\
\hline Secondary therapy costs & 1.96 & 1.94 & 1.92 & 1.90 & 1.96 & 1.83 & 1.78 & 1.75 \\
\hline Medical costs & 1.60 & 1.58 & 1.56 & 1.55 & 1.60 & 1.58 & 1.56 & 1.55 \\
\hline Adverse event costs & 0.08 & 0.08 & 0.08 & 0.08 & 0.08 & 0.08 & 0.08 & 0.08 \\
\hline Mortality costs & 1.24 & 1.23 & 1.21 & 1.20 & 1.24 & 1.23 & 1.21 & 1.20 \\
\hline Total Costs & 19.22 & 19.01 & 18.80 & 18.59 & 19.22 & 19.07 & 18.87 & 18.67 \\
\hline
\end{tabular}

Notes: XVd, selinexor + bortezomib + dexamethasone; DPd, daratumumab + pomalidomide + dexamethasone; DRd, daratumumab + lenalidomide + dexamethasone ; EPd, elotuzumab + pomalidomide + dexamethasone; KRd, carfilzomib + lenalidomide + dexamethasone; IRd, ixazomib, lenalidomide, and dexamethasone; Vd, bortezomib + dexamethasone; Rd, lenalidomide + dexamethasone; DAR, daratumumab; DRVd, daratumumab + lenalidomide + bortezomib + dexamethasone; Pd, pomalidomide + dexamethasone. 
Status Quo

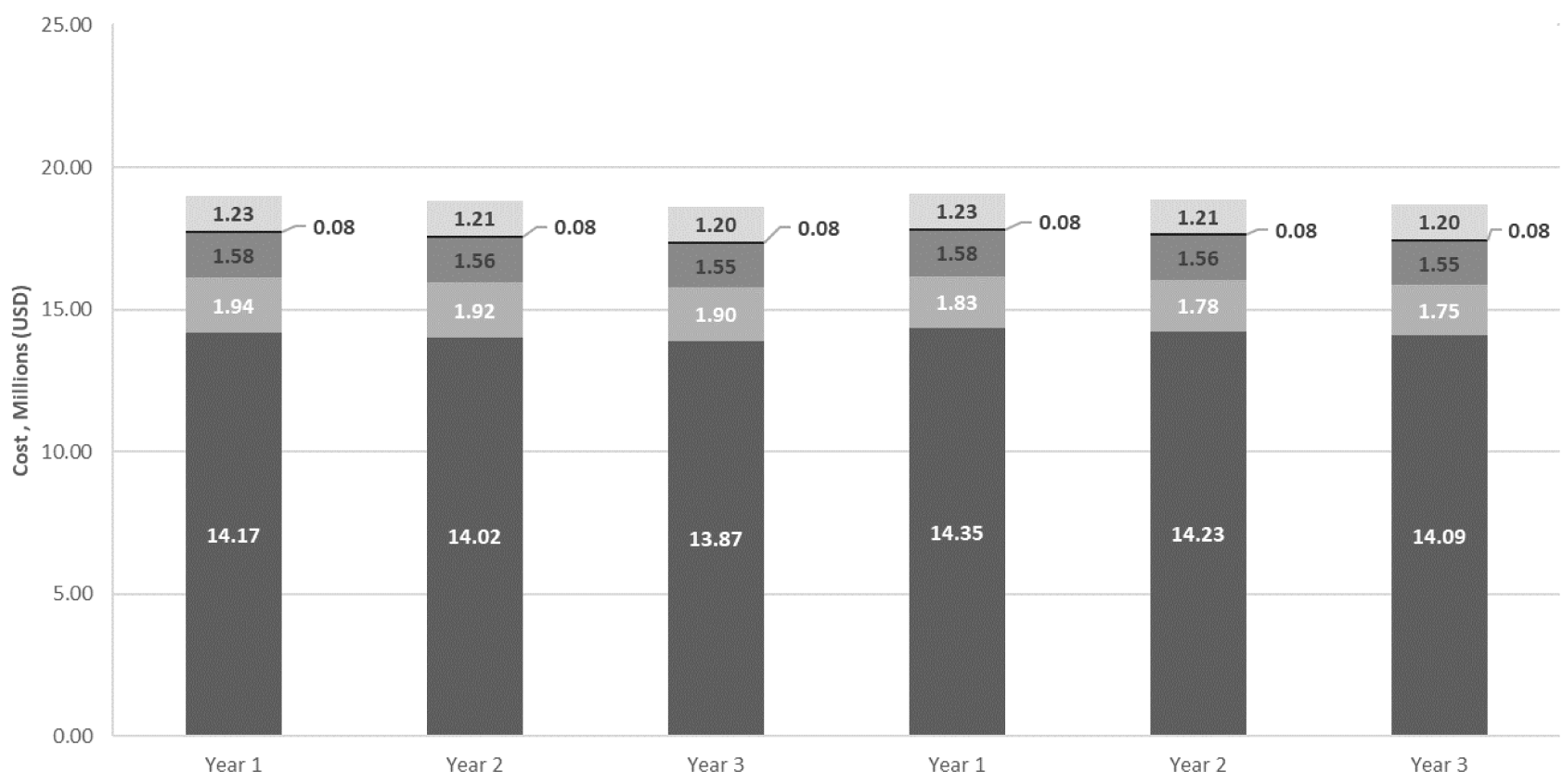

- Total Primary Therapy costs $\quad$ Secondary therapy costs Medical costs $\quad$ Adverse event costs Mortality costs

Figure 2 Private Payer Perspective: Total Costs Status Quo vs XVd Scenario (Millions, USD).

From a Medicare perspective, the absolute budget impact years 1, 2, 3, and in total, respectively (Supplementary (Millions, USD) of including XVd was \$29.68, \$36.62, Figure 2). This translated to a PMPM budget impact of $\$ 39.42$ and $\$ 105.72$ for years $1,2,3$, and in total, respec- $\$ 0.041, \$ 0.051, \$ 0.054$, and $\$ 0.049$ (USD), for years 1,2 , tively (Supplementary Figure 1). The relative budget impact $\quad 3$, and in total, respectively. The major factor for the increase of including XVd was $0.33 \%, 0.40 \%, 0.43 \%$, and $0.38 \%$ for in budget impact was increased primary therapy cost, but

Table 2 Budget Impact

\begin{tabular}{|c|c|c|c|c|c|c|}
\hline & & Baseline & Year I & Year 2 & Year 3 & Total \\
\hline \multicolumn{7}{|c|}{ Private Payer Perspective } \\
\hline \multirow[t]{4}{*}{ Healthcare System } & & & & & & \\
\hline & Absolute Budget Impact (Millions, USD) & 0.00 & 0.06 & 0.07 & 0.08 & 0.22 \\
\hline & Relative Budget Impact (\%) & 0.00 & 0.33 & 0.40 & 0.43 & 0.38 \\
\hline & Per Member Per Month & & 0.005 & 0.006 & 0.007 & 0.006 \\
\hline \multicolumn{7}{|l|}{ Medicare Perspective } \\
\hline \multirow[t]{4}{*}{ Healthcare System } & & & & & & \\
\hline & Absolute Budget Impact (Millions, USD) & 0.00 & 29.68 & 36.62 & 39.42 & 105.72 \\
\hline & Relative Budget Impact (\%) & 0.00 & 0.33 & 0.40 & 0.43 & 0.38 \\
\hline & Per Member Per Month & & 0.041 & 0.051 & 0.054 & 0.049 \\
\hline
\end{tabular}


this was partially offset by lower secondary therapy, medical costs, and mortality costs.

\section{One-Way Sensitivity Analysis Results}

The sensitivity analyses showed general consistency with the base-case findings, with the greatest sensitivity from variations in drug prices and overall survival estimates. These results are presented in Supplementary Figure 3 and Supplementary Table 6.

\section{Discussion}

Determining the potential budget impact of new treatments is essential for payers to assess the value of new therapies and manage healthcare costs. This budget impact model assessed the projected costs of adopting XVd for patients with previously treated MM from the private third-party payer and Medicare perspective in the US. For a hypothetical private third-party payer with a total plan population of 1,000,000 members, the budget impact was estimated to be $\$ 0.22$ (Millions, USD) over a three-year period. The PMPM cost was estimated to be $\$ 0.006$ in year 3. For Medicare, with a total population of $59,499,015$ members at the baseline year, the budget impact was estimated to be $\$ 105.72$ million over a threeyear period, with a PMPM cost of $\$ 0.049$ in year 3 .

A previous study evaluating the budget impact of selinexor, which this analysis was extended upon, was conducted using selinexor's previously approved indication (penta-refractory MM). ${ }^{19}$ Bassali et al (2020) found that, when considering third-line or greater patients, the cost was $\$ 0.0488$ for a hypothetical private payer plan with $1,000,000$ members and four eligible patients; the PMPM cost was estimated at $\$ 0.0103$ in year 3, and total costs per month were estimated to be $\$ 4,476 .{ }^{19}$ The budget impact of other therapy options for patients with previously treated MM have been performed. Shao et al (2016), using an administrative claims database to assess the cost of therapy for patients with $\mathrm{MM}$ in the third-line of therapy, identified total costs per month ranging from $\$ 13,377$ to $\$ 25,850$ for lenalidomide, bortezomib, carfilzomib, and pomalidomide based regimens corresponding to total inpatient costs, outpatient costs and pharmacy costs. ${ }^{42}$ Similarly, Hollman et al (2019) assessed different triplet regimens over a one-year time horizon and found total costs per month ranging from $\$ 13,890$ to $\$ 27,342$ for daratumumab, elotuzumab, carfilzomib, and ixazomibbased regimens. ${ }^{43}$ In a previous assessment of PMPM costs, Hollmann et al studied the budget impact of adding daratumumab to combination therapy regimens from the perspective of a private third-party payer in the US over a one-year time horizon and found total drug-administration - and TEAE management- costs estimated to be $\$ 0.08$. $^{44}$ Similarly, Potluri et al (2016) estimated a PMPM budget impact of $\$ 0.032$ in year 1 for the introduction of elotuzumab (9.7\% uptake) in combination with lenalidomide and dexamethasone in a hypothetical private third-party payer plan with 1,000,000 members and an estimated 29 eligible patients. ${ }^{45}$ Compared to these regimens, XVd offers clinical benefit at relatively lower PMPM (\$0.006 [USD]) at year 3) and similar total monthly treatment costs per patient $(\$ 29,813)$.

The global phase 3 trial (BOSTON) demonstrated the efficacy and safety of $\mathrm{XVd}$ for patients with previously treated MM. ${ }^{11,12}$ The safety profile of XVd allows for management of adverse events, avoiding costly emergency care and hospitalization. The once-weekly XVd regimen, in which weekly oral selinexor replaces one of the twiceweekly doses of bortezomib (and thereby reduces required clinic visits), represents a simplification of bortezomib-based triplets for previously treated MM. Compared to $\mathrm{Vd}$ (and previous Vd-based triplets), XVd offers several benefits to vulnerable patients: less overall bortezomib use, reduced dexamethasone, reduced neuropathy rates, and fewer clinic visits and their associated risks. Treatment regimens such as $\mathrm{XVd}$, with oral components and reduced time requirements for administration of therapies have been shown to be the strongest predictors of treatment satisfaction in previously treated MM. ${ }^{45}$ Such oral regimens are reportedly more convenient, improving adherence, reducing the cost associated with the number of medical visits per month, time spent in travel, waiting, and receiving treatment that non-oral therapies require. ${ }^{46}$ Increases in drug costs associated with the uptake of XVd are partially offset by lower secondary therapy, routine healthcare, and mortality costs. For example, the addition of selinexor to $\mathrm{Vd}$ is associated with significantly reduced rates of any grade and Grade $\geq 2 \mathrm{PN}$, common with higher bortezomib dose regimens, which is associated with higher costs and healthcare resource utilization in patients with MM. ${ }^{12,47}$ Patients receiving XVd in BOSTON showed persistent reductions in pain as reported in the European Organization for Research and Treatment of Cancer (EORTC) quality of life questionnaire, whereas patients receiving $\mathrm{Vd}$ reported increased pain after 60 days on treatment, likely due to bortezomib-induced PN. ${ }^{13}$ In addition to this, XVd patients reported significantly lower sensory symptom scores on the EORTC chemotherapy-induced PN scale, with a trend towards reduced motor symptom scores while 
patients receiving $\mathrm{Vd}$ experienced a faster rate of sensory symptom worsening and a trend to faster worsening of motor symptoms. ${ }^{13}$

The treatment landscape for previously treated MM is evolving with new treatment modalities such as chimeric antigen T-cell (CAR-T) therapy and therapies targeting B-cell antigen maturation factor (BCMA). ${ }^{48}$ Given the evolving landscape, the budget impact of $\mathrm{XVd}$ and its market share can be expected to shift over time.

These findings suggest a limited budget impact resulting from the introduction of selinexor into a US private thirdparty payer plan and Medicare. The once weekly XVd regimen for patients with previously treated MM patients has been shown to provide deep and durable clinical benefits regardless of prior therapy. Results of the BOSTON trial showed a $30 \%$ reduction in risk of disease progression (median PFS of 13.93 months vs 9.46 months, $\mathrm{p}=0.0075$ ), improved ORR ( $76.4 \%$ vs $63.3 \%, p=0.0012)$ vs $\mathrm{Vd}$ alone and improved median time to next treatment; which was significantly longer with XVd vs Vd (16.3 months vs 10.84 months, $\mathrm{p}=0.0012) .{ }^{12}$ In addition to this, $\mathrm{XVd}$ is the first triplet regimen with a lower neuropathy rate than standard doublet Vd: the once-weekly dosing used in the BOSTON $\mathrm{XVd}$ arm was associated with significantly lower rates and severity of bortezomib-induced PN compared with twiceweekly Vd (all grades, $32.3 \%$ vs $47.1 \%$, $\mathrm{p}=0.001$ ). ${ }^{31}$ Given that the evolving treatment landscape in MM is highly complex with multiple combinations used across lines of therapy, patients require a long-term, dynamic, individualized treatment plan. As early as first relapse, patients may have already been treated with an IMiD, a PI, and/or an anti-CD38 monoclonal antibody; currently, there are no new mechanisms approved for early-line treatment, limiting how MM cells can be attacked. With only a limited budget impact, XVd provides a novel mechanism of action and has shown clinical benefits in patients with previously treated MM. ${ }^{49}$

\section{Limitations}

This study assessed both direct costs associated with $\mathrm{XVd}$ treatment, variations in market uptake, drug price, mortality, clinical response, and treatment duration. While the current model is quite comprehensive, it does have some limitations. Medical resource utilization data were based on external literature sources which, while based on studies in previously treated MM, may not be totally aligned with the BOSTON clinical trial population. Furthermore, clinical data were also obtained from externally published literature. As homogenous data sources are necessary for internal consistency, this gap may be considered a potential limitation of this analysis. Lastly, the model's patient pathway is based on an incidence structure which affects the number of patients receiving treatment and the duration of secondary therapy. The incidence structure is a technique used to facilitate efficient modeling, yet it omits a proportion of patients who receive treatment for a duration longer than 1 year. Additionally, mortality is applied at 12 months which may introduce a partial overestimation of all other costs as patients may die at any timepoint before 12 months.

\section{Conclusion}

This study determined that XVd has a relatively small and manageable budget impact for a private third-party US payer and Medicare. To optimize outcomes in MM, treatments must consider patient age, comorbidities, cytogenetic risk, and response to prior therapies. ${ }^{50} \mathrm{XVd}$ provides clinical and humanistic benefits for some patients with previously treated MM, consistently showing superior clinical benefit compared to $\mathrm{Vd}$ across various patient subgroups (elderly, frail, bortezomib-naïve, lenalidomidepretreated patients, and in patients with high-risk cytogenetics) and fulfilling a previously unmet need for this population with a relatively low PMPM impact. ${ }^{51}$

\section{Abbreviations}

AMCP, Academy of Managed Care Pharmacy; ASCO, American Society of Clinical Oncology; BCMA, B-cell antigen maturation factor; CAR-T, chimeric antigen T-cell; DAR, daratumumab; DOR, duration of response; DPd, daratumumab, pomalidomide, and dexamethasone; DRd, lenalidomide and dexamethasone; DRVd, daratumumab, lenalidomide, bortezomib, and dexamethasone; EORTC, European Organization for Research and Treatment of Cancer; EPd, elotuzumab, pomalidomide, and dexamethasone; FDA, Food and Drug Administration; HRQoL, health-related quality of life; KRd, carfilzomib, lenalidomide, and dexamethasone; IMiD, immunomodulatory agents; IRd, ixazomib, lenalidomide, and dexamethasone; ISPOR, International Society for Pharmacoeconomics and Outcomes Research; Mg, milligram; $\mathrm{MM}$, multiple myeloma; ORR, objective response rate; OS, overall response; Pd, pomalidomide and dexamethasone; PFS, progression-free survival; PMPM, per-member-per-month; PN, peripheral neuropathy; PI, proteasome inhibitors; Rd, lenalidomide and dexamethasone; SC, subcutaneously; SCT, stem cell transplantation; SINE, selective inhibitor of nuclear export; TEAE, treatment-emergent adverse event; US, United States; USD, US dollar; VGPR, very good partial response; 
$\mathrm{Vd}$, bortezomib and dexamethasone; WAC, wholesale acquisition costs; XVd, selinexor, bortezomib, and dexamethasone.

\section{Ethical Declaration}

Review and approval by an institutional review board or ethics committee was not required for this research. The research does not involve patients/people, medical records, or human samples. The data presented in this publication are publicly available.

\section{Acknowledgments}

Rekar K. Taymour provided writing and editorial support.

\section{Funding}

This study was funded by Karyopharm Therapeutics.

\section{Disclosure}

H. Leong is an employee of Karyopharm Therapeutics. M. Dolph and G. Tremblay are employees of Purple Squirrel Economics, which received funding from Karyopharm Therapeutics to conduct this study. The authors report no other conflicts of interest in this work.

\section{References}

1. American Cancer Society. Cancer Facts \& Figures; 2020. Available from: https://www.cancer.org/research/cancer-facts-statistics/all-cancer-factsfigures/cancer-facts-figures-2020.html. Accessed January 23, 2020.

2. Millennium Pharmaceuticals, Inc. Velcade ${ }^{\circledR}$ (bortezomib) injection [Prescribing Information]. Millennium Pharmaceuticals, Inc; 2019.

3. National Comprehensive Cancer Network. $\mathrm{NCCN}^{\circledR}$ clinical practice guidelines in oncology $\left(\mathrm{NCCN}\right.$ guidelines ${ }^{\circledR}$ ) for antiemesis. (Version 2.2020). National Comprehensive Cancer Network (NCCN); 2020.

4. Claxton AJ, Cramer J, Pierce C. A systematic review of the associations between dose regimens and medication compliance. Clin Ther. 2001;23(8):1296-1310. doi:10.1016/S0149-2918(01)80109-0

5. Grammatico S, Cesini L, Petrucci MT. Managing treatment-related peripheral neuropathy in patients with multiple myeloma. Blood Lymphat Cancer. 2016;6:37. doi:10.2147/BLCTT.S91251

6. Dimopoulos MA, Moreau P, Palumbo A, et al. Carfilzomib and dexamethasone versus bortezomib and dexamethasone for patients with relapsed or refractory multiple myeloma (ENDEAVOR): a randomised, phase 3, open-label, multicentre study. Lancet Oncol. 2016;17(1):27-38. doi:10.1016/S1470-2045(15)00464-7

7. Palumbo A, Chanan-Khan A, Weisel K, et al. Daratumumab, bortezomib, and dexamethasone for multiple myeloma. $N$ Engl $J$ Med. 2016;375(8):754-766. doi:10.1056/NEJMoa1606038

8. Hu B, Zhou Q, Hu YY, et al. Efficacy and safety of once-weekly versus twice-weekly bortezomib in patients with hematologic malignancies: a meta-analysis with trial sequential analysis. Pharmacotherapy. 2019;39(6):697-708. doi:10.1002/phar.2267

9. Richardson PG, Sonneveld P, Schuster M, et al. Extended follow-up of a phase 3 trial in relapsed multiple myeloma: final time-to-event results of the APEX trial. Blood J Am Soc Hematol. 2007;110 (10):3557-3560.
10. Bringhen S, Larocca A, Rossi D, et al. Efficacy and safety of once-weekly bortezomib in multiple myeloma patients. Blood $\mathrm{J} \mathrm{Am}$ Soc Hematol. 2010;116(23):4745-4753.

11. Karyopharm Therapeutics. XPOVIO (selinexor) [prescribing information]. XPOVIO (Selinexor). Available from: https://www.karyo pharm.com/wp-content/uploads/2019/07/NDA-212306-SN-0071Prescribing-Information-01July2019.pdf. Accessed May 26, 2021.

12. Grosicki S, Simonova M, Spicka I, et al. Once-per-week selinexor, bortezomib, and dexamethasone versus twice-per-week bortezomib and dexamethasone in patients with multiple myeloma (BOSTON): a randomised, open-label, phase 3 trial. Lancet. 2020;396 (10262):1563-1573. doi:10.1016/S0140-6736(20)32292-3

13. Sanchez L, Leleu X, Beaumont J, et al. Peripheral neuropathy symptoms, pain and functioning in relapsed or refractory multiple myeloma patients treated with selinexor, bortezomib, and dexamethasone In: 62nd American Society of Hematology Annual Meeting and Exposition. 2020.

14. National Institutes of Health. Surveillance, epidemiology, and end results program. multiple myeloma incidence rates per 100,000, SEER 13.

15. Runyan A, Banks J, Bruni DS. Current and future oncology management in the United States. J Manag Care Spec Pharm. 2019;25 (2):272-281. doi:10.18553/jmcp.2019.25.2.272

16. Fonseca R, Abouzaid S, Bonafede M, et al. Trends in overall survival and costs of multiple myeloma, 2000-2014. Leukemia. 2017;31 (9):1915-1921. doi:10.1038/leu.2016.380

17. Djatche LM, Goble JA, Chun G, Varga S. Evaluating oncology value-based frameworks in the US marketplace and challenges in real-world application: a multiple myeloma test case. J Manag Care Spec Pharm. 2018;24(1):39-46. doi:10.18553/jmcp.2018.24.1.39

18. Schnipper LE, Davidson NE, Wollins DS, et al. Updating the American Society of Clinical Oncology value framework: revisions and reflections in response to comments received. J Clin Oncol. 2016;34(24):2925-2934. doi:10.1200/JCO.2016.68.2518

19. Bassali J, Gould IG, Kaye JA, Mladsi D, Mehta J. US budget impact model for selinexor in relapsed or refractory multiple myeloma. Clinicoecon Outcomes Res. 2020;12:317. doi:10.2147/CEOR. S251070

20. Sullivan SD, Mauskopf JA, Augustovski F, et al. Budget impact analysis-principles of good practice: report of the ISPOR 2012 budget impact analysis good practice II task force. Value Health. 2014;17(1):5-14. doi:10.1016/j.jval.2013.08.2291

21. Mauskopf JA, Sullivan SD, Annemans L, et al. Principles of good practice for budget impact analysis: report of the ISPOR task force on good research practices - budget impact analysis. Value Health. 2007;10(5):336-347. doi:10.1111/j.1524-4733.2007.00187.x

22. The AMCP format for formulary submissions, version 3.1. A format for submission of clinical and economic evidence of pharmaceuticals in support of formulary consideration. December 2012.

23. MacEwan JP, Batt K, Yin W, et al. Economic burden of multiple myeloma among patients in successive lines of therapy in the United States. Leuk Lymphoma. 2018;59(4):941-949. doi:10.1080/ 10428194.2017.1361035

24. United Stated Bureau of Labor Statistics. Disease based price index neoplasm diseases. Available from: https://www.bls.gov/pir/disease home.htm. Accessed May 14, 2021.

25. Kaiser Family Foundation. Medicare beneficiaries as a percent of total population. Available from: https://www.kff.org/medicare/stateindicator/medicare-beneficiaries-as-of-total-pop/?currentTimeframe= 0\&sortModel=\%7B $\% 22$ colId $\% 22: \% 22$ Location $\% 22, \% 22$ sort $\% 22: \%$ 22asc\%22\%7D. Accessed May 14, 2021

26. AnalySource Drug Pricing Resource, 2020. Available from: https:// www.analysource.com. Accessed January 2020.

27. Mauskopf J, Earnshaw SR, Brogan A, Wolowacz S, Brodtkorb T-H. Budget-Impact Analysis of Health Care Interventions. Springer; 2017. 
28. Janssen Pharmaceutical Companies. DARZALEX (daratumumab) [prescribing information]. U.S. Food and Drug Administration website. Available from: https://www.accessdata.fda.gov/drugsatfda_ docs/label/2018/761036s013lbl.pdf. Accessed March 2019.

29. Voorhees PM, Kaufman JL, Laubach J, et al. Daratumumab, lenalidomide, bortezomib, and dexamethasone for transplant-eligible newly diagnosed multiple myeloma: the GRIFFIN trial. Blood. 2020;136(8):936-945. doi:10.1182/blood.2020005288

30. Attal M, Richardson PG, Rajkumar SV, et al. Isatuximab plus pomalidomide and low-dose dexamethasone versus pomalidomide and low-dose dexamethasone in patients with relapsed and refractory multiple myeloma (ICARIA-MM): a randomised, multicentre, open-label, phase 3 study. Lancet. 2019;394(10214):2096-2107. doi:10.1016/S0140-6736(19)32556-5

31. Siegel DS, Schiller GJ, Samaras C, et al. Pomalidomide, dexamethasone, and daratumumab in relapsed refractory multiple myeloma after lenalidomide treatment. Leukemia. 2020;34(12):3286-3297. doi:10.1038/s41375-020-0813-1

32. Dimopoulos MA, San-Miguel J, Belch A, et al. Daratumumab plus lenalidomide and dexamethasone versus lenalidomide and dexamethasone in relapsed or refractory multiple myeloma: updated analysis of POLLUX. haematologica. 2018;103(12):2088. doi:10.3324/ haematol.2018.194282

33. Dimopoulos MA, Dytfeld D, Grosicki S, et al. Elotuzumab plus pomalidomide and dexamethasone for multiple myeloma. $N$ Engl J Med. 2018;379(19):1811-1822. doi:10.1056/NEJMoa1805762

34. Dimopoulos MA, Stewart AK, Masszi T, et al. Carfilzomib-lenalidomide-dexamethasone vs lenalidomide-dexamethasone in relapsed multiple myeloma by previous treatment. Blood Cancer J. 2017;7(4): e554-e554. doi:10.1038/bcj.2017.31

35. Hou J, Jin J, $\mathrm{Xu} \mathrm{Y,} \mathrm{et} \mathrm{al.} \mathrm{Randomized,} \mathrm{double-blind,}$ placebo-controlled Phase III study of ixazomib plus lenalidomide-dexamethasone in patients with relapsed/refractory multiple myeloma: China continuation study. J Hematol Oncol. 2017;10(1):1-13. doi:10.1186/s13045-017-0501-4

36. Karyopharm Therapeutics, Inc. Selinexor brand impact multiple myeloma treatment topline report. Internal data on file. 2020.

37. Karyopharm Therapeutics Inc. Clinical study report KCP-330-023. 2020.

38. US Department of Health and Human Services. Agency for healthcare research and quality. HCUPnet. Healthcare Cost and Utilization Project; 2017.

39. Buck CJ. 2017 HCPCS Level II Professional Edition-E-Book. Elsevier Health Sciences; 2017.

40. US Census Bureau Population Division. Annual estimates of the resident population for selected age groups by sex for the United States: April 1, 2010 to July 1, 2019 (NC-EST2019-AGESEX). 2019.
41. Pelligra CG, Parikh K, Guo S, et al. Cost-effectiveness of pomalidomide, carfilzomib, and daratumumab for the treatment of patients with heavily pretreated relapsed-refractory multiple myeloma in the United States. Clin Ther. 2017;39(10):1986-2005. doi:10.1016/j. clinthera.2017.08.010

42. Shao C, Monberg M, Cao X, Zhou W, Zhong Y, Marinello P. Realworld treatment patterns, health care utilization, and costs among relapsed/refractory multiple myeloma (rrMM) patients. Washington, DC: American Society of Hematology; 2016.

43. Hollmann S, Moldaver D, Goyert N, Grima D, Maiese EM. A US cost analysis of triplet regimens for patients with previously treated multiple myeloma. J Manag Care Spec Pharm. 2019;25(4):449-459. doi:10.18553/jmcp.2019.25.4.449

44. Hollmann S, Goyert N, Moldaver D, Grima D, Maiese E. U.S. budget impact analysis for daratumumab in combination with lenalidomide and dexamethasone, bortezomib and dexamethasone, or pomalidomide and dexamethasone for the treatment of patients with relapsed/ refractory multiple myeloma. J Manag Care Spec Pharm. 2017;23: S32. doi:10.18553/jmcp.2017.23.10-a.s1

45. Potluri R, Bhandari H, Ranjan S, Chen C. Budget impact analysis of introducing elotuzumab in combination with lenalidomide and dexamethasone for relapsed/refractory multiple myeloma: a US payer perspective. Washington, DC: American Society of Hematology; 2016.

46. Chari A, Romanus D, DasMahapatra P, et al. Patient-reported factors in treatment satisfaction in patients with relapsed/refractory multiple myeloma (RRMM). Oncologist. 2019;24(11):1479. doi:10.1634/ theoncologist.2018-0724

47. Song X, Wilson KL, Kagan J, Panjabi S. Cost of peripheral neuropathy in patients receiving treatment for multiple myeloma: a US administrative claims analysis. Ther Adv Hematol. 2019;10:2040620719839025. doi:10.1177/2040620719839025

48. Shah N, Chari A, Scott E, Mezzi K, Usmani SZ. B-cell maturation antigen (BCMA) in multiple myeloma: rationale for targeting and current therapeutic approaches. Leukemia. 2020;34(4):985-1005. doi:10.1038/s41375-020-0734-z

49. Kumar SK, Callander NS, Hillengass J, et al. NCCN guidelines: multiple myeloma, version 6.2021. J Natl Compr Canc Netw. 2021.

50. Harousseau JL, Dreyling M. Multiple myeloma: ESMO clinical practice guidelines for diagnosis, treatment and follow-up. Ann Oncol. 2010;21:v155-v157. doi:10.1093/annonc/mdq178

51. Patel K, Parker T, Mengyang D, Bar N, Huntington S, Giri S. Costeffectiveness of once-weekly selinexor, bortezomib, and dexamethasone (XVd) versus twice-weekly bortezomib and dexamethasone (Vd) in relapsed or refractory multiple myeloma. 2020.
ClinicoEconomics and Outcomes Research

\section{Publish your work in this journal}

ClinicoEconomics and Outcomes Research is an international, peerreviewed open-access journal focusing on Health Technology Assessment, Pharmacoeconomics and Outcomes Research in the areas of diagnosis, medical devices, and clinical, surgical and pharmacological intervention. The economic impact of health policy and health systems organization also constitute important areas of coverage. The manuscript management system is completely online and includes a very quick and fair peer-review system, which is all easy to use. Visit http://www.dovepress.com/testimonials.php to read real quotes from published authors. 